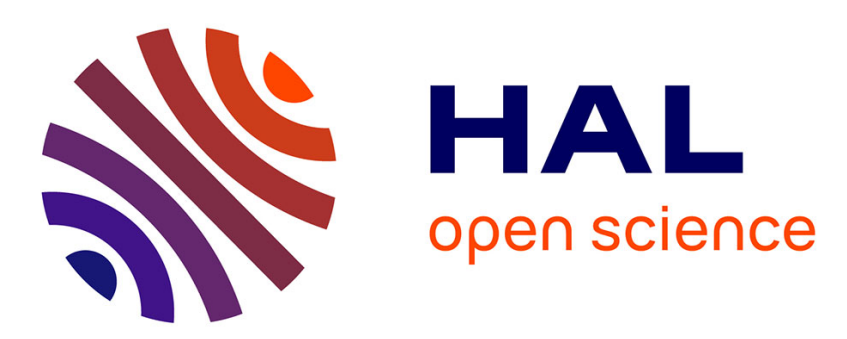

\title{
Undernutrition Prevention for Disabled and Elderly People in Smart Home with Bayesian Networks and RFID Sensors
}

Nathalie D. Cislo

\section{> To cite this version:}

Nathalie D. Cislo. Undernutrition Prevention for Disabled and Elderly People in Smart Home with Bayesian Networks and RFID Sensors. 8th International Conference on Smart Homes and Health Telematics, ICOST 2010, Jun 2010, Seoul, South Korea. pp.246 - 249. hal-00600423

\section{HAL Id: hal-00600423 https://hal.science/hal-00600423}

Submitted on 14 Jun 2011

HAL is a multi-disciplinary open access archive for the deposit and dissemination of scientific research documents, whether they are published or not. The documents may come from teaching and research institutions in France or abroad, or from public or private research centers.
L'archive ouverte pluridisciplinaire HAL, est destinée au dépôt et à la diffusion de documents scientifiques de niveau recherche, publiés ou non, émanant des établissements d'enseignement et de recherche français ou étrangers, des laboratoires publics ou privés. 


\title{
Undernutrition Prevention for Disabled and Elderly People in Smart Home with Bayesian Networks and RFID Sensors
}

\author{
Nathalie Cislo, \\ PRISME Institute, University of Orleans, \\ 63, avenue de Lattre de Tassigny, 18020 Bourges Cedex, France, \\ Nathalie.Cislo@bourges.univ-orleans.fr
}

\begin{abstract}
Undernutrition prevention or detection for disabled or elderly people must be performed rapidly to avoid irremediable consequences. In this paper a classification of uncertainties centered on a meal notion is first proposed. Two of these uncertainties are developed in a smart home and homecare context. Meal preparation probability is evaluated by a simulation based on Naïve Bayesian Networks. To determine if a person is at risk of malnutrition or undernutrition, and to supervise prepared meal quality and quantity in terms of nutrients, the use of RFID tags is discussed, bringing many open issues for which additional sensors are proposed. This research work was initiated in a collaborative project called CaptHom.
\end{abstract}

Keywords: Smart Home, Undernutrition Prevention, Bayesian Networks, RFID Sensors, Gerontechnologies, Disabled People, Elderly People.

\section{Introduction}

If many works deal with smart home, especially for fragile people, few researches are focused on what happens particularly in the kitchen [1], [2], [3]. The nutrition issue for disabled or elderly people, from a physiological point of view, rather than from a cognitive point of view is still a research niche. However, malnutrition, an insufficient, excessive or imbalanced consumption of nutrients [4], is a major concern in geriatrics: many clinicians agree that 5 to $10 \%$ of elderly people at home, $50 \%$ in hospital and up to 70 to $80 \%$ in geriatric institution suffer from undernutrition [5].

The work on undernutrition presented in this paper was initiated in a collaborative project called CaptHom with an aspect dedicated to homecare for fragile people.

In the second section is presented a classification of uncertainties, centered on the notion of "meal", in order to avoid undernutrition. In section three undernutrition prevention is proposed with Bayesian Networks and results of a simulation to detect a meal preparation are presented. Then, the use of RFID sensors is discussed in the fourth section to identify what food was prepared and eaten, and which quantity and quality in terms of nutrients. Many open issues are listed, that introduce perspectives developed in section five after conclusion. 


\section{Undernutrition Prevention}

Because undernutrition can be irremediate, the goal is undernutrition prevention or detection, as soon as possible. When elderly people or disabled people are at home, the issue is to deal with three uncertainties, centered on the meal notion (Fig. 1): (1) a meal was prepared, (2) the meal was really eaten, totally or partially, (3) the person does not suffer from undernutrition in spite of a sufficient quantity of food : meal quality is sufficient.

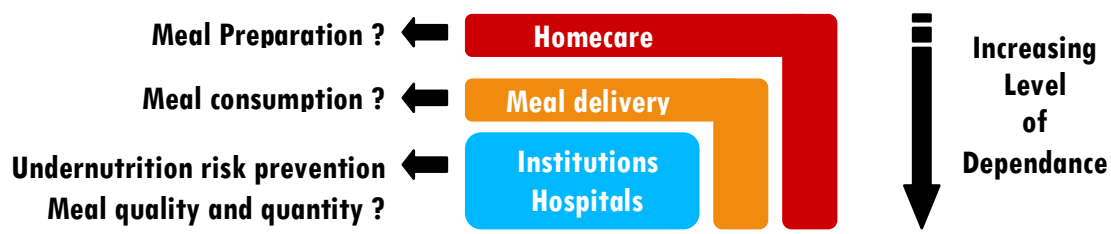

Fig. 1. Classification of uncertainties to verify in order to prevent undernutrition, corresponding to different levels of dependance.

In institution or in hospital it is theoretically possible to prevent or to detect undernutrition. When meals are delivered at home, a human being can still verify if the patient eats. But when people are cooking, in a homecare context, control is difficult if a camera is out of question for ethics concern. Answers to issues occurring with less dependant people can be applied to more dependant patients (Fig. 1). For instance automatic weight control in homecare context can be exported to institutions or hospitals.

\section{Bayesian Networks for Undernutrition Prevention}

According to the State of the Art on existing IA or Control tools presented in [6], Bayesian Networks (BN) are a good solution to deal with uncertainty. DAGs (Directed Acyclic Graphs) have an additive advantage: they are very easily understandable, even by non-programmers, they can facilitate communication between researchers and clinicians.

An inconvenience, when a Bayesian Network is constructed, is that a learning is needed, or an expert advice.

We first focused on meal preparation, in order to know the probability that a person prepared a meal. The chosen Bayesian Networks are naïve $B N$, a very simple form of trees, where dependences between son nodes are neglected (which is not true in real life), avoiding then unnecessary computing, but giving good results.

To know if a meal is prepared a list of non exhaustive events are observed: presence in the kitchen, refrigerator opening, tap flowing, cupboard opening, garbage can opening, gas stove or electric cooker ON, time, duration...

To perform the conditional probabilities learning, for instance to know which is the probability to have a meal preparation according to the fact that the refrigerator is opened and closed, the person must be observed. The worst solution is to ask the 
person to write each action in the kitchen with date and time; the best one, but the most complex, is to automatically register this information with relevant sensors.

Key-actions (or key-events) have to be defined too, for instance, refrigerator opening. To have a significant information, a number of key-actions must be detected in a given time: if someone is present in the kitchen, opens the refrigerator, switches the cooker on, between 6 and 9 in the morning, in less than 60 minutes, one can conclude that the probability that someone has prepared a breakfast is very high.

A simulation of the situation described below was done with the Bayesian Network Toolbox (BNT) of Matlab. Table 1 gives a subset of conditional probabilities according to an evaluation of adults activities in a kitchen. The simulation result is a probability equal to 0.9 to have a meal preparation.

Table 1. A priori conditional probabilities for events in the kitchen

\begin{tabular}{|c|c|}
\hline $\mathrm{P}(\mathrm{m}=\mathrm{F})$ & $\mathrm{P}(\mathrm{m}=\mathrm{T})$ \\
\hline 0,8 & 0,2 \\
\hline
\end{tabular}

$m$ : meal preparation, $k$ : kitchen, $f$ : refrigerator, c: cooker, F: false, $T$ : true

\begin{tabular}{|c|c|c|}
\hline $\mathrm{m}$ & $\mathrm{P}(\mathrm{k}=\mathrm{F})$ & $\mathrm{P}(\mathrm{k}=\mathrm{T})$ \\
\hline $\mathrm{F}$ & 0,8 & 0,2 \\
\hline $\mathrm{T}$ & 0,1 & 0,9 \\
\hline
\end{tabular}

\begin{tabular}{|c|c|c|}
\hline $\mathrm{m}$ & $\mathrm{P}(\mathrm{c}=\mathrm{F})$ & $\mathrm{P}(\mathrm{c}=\mathrm{T})$ \\
\hline $\mathrm{F}$ & 0,9 & 0,1 \\
\hline $\mathrm{T}$ & 0,05 & 0,95 \\
\hline
\end{tabular}

\section{RFID Sensors for Undernutrition Prevention}

In a Smart Home, to be sure that a fragile person really eats a prepared meal, and is not at risk of undernutrition, it is needed to know what food was prepared and eaten, which quantity and quality in terms of nutrients, and to keep weight records.

Control of events in smart kitchen is done with a high variety of sensors: opening and closing detectors (for refrigerator, cupboards, drawers...), presence sensors like the CaptHom device, flowmeters, accelerometers, supervisor, pressure sensors, thermometers, smoke sensors, light sensors, GPS devices, RFID sensors...

In order to keep track of different pieces of food in a kitchen, the proposal is to stick RFID tags [7] [8] on strategically chosen pieces of food, because these are either easy to tag or relevant (caloric food, with proteins, nutrients...).

RFID sensors in the kitchen bring many open issues:

1. A frequent inventory is needed and a human intervention is intrusive, high-cost

2. The RFID system software must discriminate if articles out of a cupboard are needed in a recipe, or were momentarily out. The time record is not sufficient, because unneeded food can stay forgotten, and come back into place, many hours or days after. The software can be coupled with a cognitive deficiency assistance.

3. RFID loops location has to be optimised to detect food in motion.

4. In some pathologies, like diabetes, a complementary system must be able to evaluate exactly how much food was prepared and eaten.

5. Vegetables and fruit are large open issues. Ink RFID does exist [9], but for the moment it is used to tag cattle, not for eatable applications.

Beside these issues weight control is a relatively easy task, assuming that there are many pressure sensors existing, placed in sofa, chair, bed, to get automatic records. 


\section{Conclusion and Perspectives}

To prevent or to rapidly detect undernutrition, a classification of uncertainties centered on a meal notion is first proposed. Two of these uncertainties are developed.

Meal preparation probability is evaluated by a simulation based on Naïve Bayesian Networks. But a learning, or an expert are needed, and events are detected by a series of sensors. Real time records have to be compared to a normal activity, in order to detect abnormal activities or a lack of activities, to raise the alarm.

To determine if a person is at risk of undernutrition, and to supervise prepared meal quality and quantity in terms of nutrients, the use of RFID tags is discussed, bringing many open issues for which additional sensors are proposed.

Encouraging results from simulation allow to begin a second phase, where conditional probabilities are learned from the records of disabled and elderly volunteers living in the $130 \mathrm{~m}^{2}$ fully equipped experimental apartment of GIS Madonah (Scientific Interest Group for Night and Day Homecare for Elderly or Disabled People), inside Bellevue Institution, in Bourges, France. Occupancy time of the kitchen is assumed to be different in adults group and in elders group, with individual variations: conditional probabilities personalization is then scheduled. The focus is made too on the comparison between recorded activity and normal activity.

Among issues presented in section 4, about RFID tags on food, on the one hand optimization for loops localization, and on the other hand smartness of the algorithm dedicated to follow up tags on food are the future goals, waiting for eatable RFID ink.

Aknowledgments: We especially thank all our partners involved in the CAPTHOM project of the S2E2 cluster (Sciences and Systems of Electrical Energy), and the French Industry Ministry and locale authorities for their financial help.

\section{References}

1. Groussard, P. Y., Pigot, H.: Cognitive modeling of a cooking activity: Integration of the Contention Scheduling Theory in the Cognitive Architecture ACT-R, In: NASTEC'2008, August 13-15, pp. 94-98 (2008).

2. Dion, A., Pigot H.: Modeling cognitive errors in the realization of an activity of the everyday life, In: Cognitio'2007, (2007)

3. Vergnès, D., Giroux, S., Chamberland-Tremblay, D.: Interactive Assistant for Activities of Daily Living, In: ICOST'2005, Sherbrooke, Canada (2005)

4. Malnutrition, In: Dorland's Medical Dictionary.

5. Martin, Y.: Malnutrition, In: IVème Journée Scientifique du Laboratoire Marcel-Mérieux, Lyon (2004)

6. Naïm, P., Wuillemin, P.-H., Leray, P., Pourret, O., Becker. A.: Réseaux bayésiens, $3^{\text {rd }}$ edition, Eyrolles (2007)

7. Ho, L., Moh, M., Walker, Z., Hamada, T., Su, C.-F.: A Prototype on RFID and Sensor Networks for Elder Healthcare: Progress Report, In: SIGCOMM'05 Workshops, Philadelphia, PA, USA, pp.70-75, ACM (2005)

8. Déploiement de solutions RFID: les bonnes pratiques pour mener à bien un projet. Rapport Ministériel, France, http://www.industrie.gouv.fr/pdf/deploiement_rfid_280206.pdf

9. RFID Ink, http://www.somarkinnovations.com 